\title{
La literatura argentina del siglo XIX, objeto de la crítica y materia de la ficción
}

The Argentinian Literature of the 19th Century, an object of criticism and a subject of fiction

A Literatura Argentina do século XIX, objeto da crítica e matéria da ficção

\section{María Rosa Lojo}

UNIVERSIDAD DE BUENOS AIRES, UNIVERSIDAD DEL SALVADOR, CONSEJO NACIONAL DE INVESTIGACIONES CIENTÍFICAS Y TÉCNICAS (CONICET), ARGENTINA

Profesora de la Universidad de Buenos Aires y de la Universidad del Salvador.

Doctora en Letras de la Universidad de Buenos Aires, Argentina. Ha

publicado numerosos artículos en revistas especializadas y es autora

de los ensayos La 'barbarie' en la narrativa argentina (siglo XIX)

(Corregidor, 1994) y Sábato: en busca del original perdido (Corregidor, 1997) y de las novelas Las libres del Sur (Sudamericana, 2004) y Finisterre

(Sudamericana, 2005). Correo electrónico:mrlojo@gmail.com

\footnotetext{
Artículo de reflexión

Documento accesible en línea desde la siguiente dirección: http://revistas.javeriana.edu.co Agradezco especialmente los aportes puntuales (señalados en las correspondientes referencias) de los investigadores Marina Guidotti, Walter Derbiz y Jimena Néspolo (miembros del PIP 0286 del que soy titular), provenientes de sus investigaciones en curso y aún inéditas.

doi:10.11144/Javeriana.CL19-37.lads
} 


\section{Resumen}

El presente artículo se propone una revisión del corpus y del canon de la literatura argentina decimonónica, que hoy se amplían y se modifican a través de nuevas escuelas y perspectivas críticas (desde el feminismo a la archivística, desde los estudios coloniales y poscoloniales a la "historia desde abajo"), y encamina hacia otra biblioteca posible del siglo XIX. Los hermanos Lucio y Eduarda Mansilla, revisitados desde la investigación académica y la reescritura creativa, emergen como la punta del iceberg de un mundo histórico y literario cuyo conocimiento está muy lejos de haber sido clausurado y agotado.

Palabras clave: siglo XIX; Lucio V. Mansilla; Eduarda Mansilla; corpus; canon; crítica; ficción

\section{Abstract}

This article intends to review the corpus and the canon of nineteenth-century Argentinian literature which are currently broadened and modified through new schools and critical perspectives (from feminism to the archival science, from Colonial and Post-colonial studies on the "history from below"), and lead us to another possible library of the 19th century. Brothers Lucio and Eduardo Mansilla, revisited from academic research and creative rewriting, emerge as the tip of the iceberg of a historical and literary world which knowledge is far from being closed or exhausted.

Key words: 19th century; Lucio V. Mansilla; Eduarda Mansilla; corpus; canon; criticism; fiction

\section{Resumo}

O presente artigo propõe uma revisão do corpus e do cânon da literatura argentina decimônica, que hoje se ampliam e se modificam através de novas escolas e perspectivas críticas (desde o feminismo até a arquivística, desde os estudos coloniais e pós-coloniais até a "história desde baixo"), e nos encaminham até outra biblioteca possível do século XIX. Os irmãos Lucio e Eduarda Mansilla, revisitados desde a investigação académica e a reescritura criativa, emergem como a ponta do iceberg de um mundo histórico e literário cujo conhecimento está muito longe de estar enclausurado e esgotado.

Palavras-chave: Século XIX; Lucio V. Mansilla; Eduarda Mansilla; corpus; cânon; crítica; ficção

RECIBIDO: 11 DE MAYO DE 2014. EVALUADO: 25 DE JULIO DE 2014. DISPONIBLE EN LÍNEA: 15 DE ENERO DE 2015.

\section{Cómo citar este artículo:}

Lojo, María Rosa. "La literatura argentina del siglo XIX: objeto de crítica y materia de

ficción". Cuadernos de Literatura 37 (2015): 285-312. doi:10.11144/Javeriana.CL19-37.lads 


\section{Escenas fundadoras y familias sustitutas}

Mis padres, españoles exiliados de la posguerra civil, no pudieron legarme, junto con la lengua, una literatura argentina que les era desconocida. Sus primeros textos fuera del aula llegaron tardíamente a mi biblioteca, con forma de bonsái. Se trataba de un regalo entre lúdico y didáctico, traído por papá, un día de Santa Rosa. De lúdico (y de bonsái) tenía el tamaño y la factura: un estante de madera, como para casa de muñecas, colmado de libritos de tapa roja. Lo didáctico atañía al contenido, proclive tanto a la edificación moral y patriótica como a la información histórico-política.

Ese "concentrado" de literatura nacional, publicado en 1962, y que yo recibí en 1968, respondía a un modelo de canon decimonónico frecuente entonces, sobre todo para los destinatarios escolares, capaz de cubrir variadas áreas discursivas y temáticas: los cimientos de la Constitución Nacional (extractos de las Bases, de Alberdi); las memorias del prócer áulico por excelencia (Recuerdos de Provincia, de Domingo Faustino Sarmiento); los discursos de un celebrado orador, también presidente de la República (un tomito de Discursos selectos, de Nicolás Avellaneda); dos de los más célebres poemas gauchescos: el trágico Fierro y el jocoso Fausto, de Estanislao del Campo; una novela de formación (la fuvenilia de Miguel Cané) e, infaltable, una semblanza del padre de la patria: San Martín y la gran epopeya, de Tomás Guido. Todos conformaban armoniosamente (parafraseando un título de Lelia Area) una ortodoxa "biblioteca para leer la nación". Entre ellos, sorprendente, una rara avis, difícil de clasificar: ni liberal propiamente dicho, ni prócer, ni didáctico. $\mathrm{Ni}$ ensayista ni novelista ni poeta, artífice de una escritura disruptiva, su voz se deslizaba hacia la anomalía miscelánea. Era Lucio V. Mansilla, el escritor que encontró la horma de su zapato, y el anillo para sus dedos de $d a n d y$, en un género francés: la causerie. Lo adaptó, como nadie, a todas las necesidades de la expresión, a todos los tonos, menos, desde luego, el de la solemnidad.

Uno de los relatos conversados que guardaba su tomo, titulado Entre-nos, me abrió, para siempre, la puerta de la literatura argentina. Se trata de "Los siete platos de arroz con leche". Aunque he contado otras veces (Lojo, "Reescribir") esta "escena de lectura" fundadora, para tratar de explicarme los motivos de una fascinación que sigue acompañándome, cada vez que releo el texto encuentro algunos nuevos. El asunto mismo es, de por sí, muy significativo. Mansilla da cuenta de un retorno: el suyo, después del largo viaje que lo llevó, a los dieciocho años, primero a Calcuta y a otros puntos de Oriente, hasta terminar en Europa. Una experiencia en verdad iniciática, dispuesta por su padre, con el objetivo de los ritos de pasaje: transformarlo en hombre y alejarlo de lecturas y amores irresponsables. 
Cuando regresa, va a rendir sus respetos a una figura central (de su familia y de la vida política argentina): su tío materno y padrino Juan Manuel de Rosas, que pronto se irá del gobierno y del país, derrocado por Urquiza. Lucio, que ha viajado sin su bendición, viene ahora a recibirla. Y, quizás en pago por la transgresión de haber partido, debe permanecer horas escuchándolo leer un voluminoso mensaje dirigido a la Legislatura. El "castigo" se completa con una especie de tortura gastronómica que comienza en forma placentera: la ingestión, a medida que su tío lee y discute el mensaje, de siete platos de arroz con leche, el primero de los cuales es traído por su prima Manuelita, hija de Rosas y primera dama de la Confederación Argentina. Como suele suceder con el autor, el episodio reverbera en el tiempo, se reinterpreta y se ramifica en colofones. Uno de ellos es la reacción del general Lucio Norberto Mansilla, que tilda de loco a su cuñado, cuando su hijo (vuelto a casa recién a la madrugada) le informa sobre la lectura, a viva voz, del mensaje descomunal. El segundo tiene lugar en Inglaterra, frente al restaurador derrotado, que le recuerda a su sobrino la escucha interminable, los "platitos" y le describe, con clarividencia pasmosa, los comentarios que supone debió hacer el general Mansilla. "Aquella visión clara, aquel conocimiento perfecto de las personas y de las cosas - concluye su sobrino- es una de las impresiones más trascendentales de mi vida", "sin esa impresión yo no habría conocido, como creo conocerla, la misteriosa y extraña personalidad de Rozas..." (L. Mansilla, Entre-Nos 100).

La puerta del caserón de Rosas y de la literatura argentina que Lucio me abrió de esta manera es también una entrada lateral a la historia patria, leída como historia de la propia familia y buceo en la memoria íntima. Mansilla es el testigo involucrado en un mundo desaparecido como la mansión de Palermo, que sus páginas reponen en el relato. ${ }^{1}$ Es el portavoz de los que fueron vencidos o pronto lo serán, y que, afuera o adentro del país, quedarán desplazados del centro del poder. Su pequeña historia se identifica con la gran historia, por fuera del triunfalismo, de la construcción de un cursus honorum perdurable, inscrito en los anales de la nación. A la inversa de los Recuerdos de provincia que el joven y ambicioso Sarmiento aspira a convertir en su pasaporte a la gloria, los recuerdos del maduro ${ }^{2}$

1 "Manuelita recibía donde ahora está el gabinete de física del Colegio Militar" (L. Mansilla, Entre-Nos 157). Cumpliendo el acto clásico del conquistador, Sarmiento había demolido y reutilizado el hogar del jefe enemigo, y lo había convertido en uno de los espacios de "control y vigilancia" del poder estatal, en el nuevo régimen.

2 Los cinco tomos de Causeries que aparecieron (Mansilla tenía nueve preparados, cuya publicación completa nunca se llevó a cabo por la falta de eco de los primeros), lo hacen entre 1889 y 1890 , cuando Lucio tenía ya entre cincuenta y ocho y sesenta años. 
Mansilla se arman con lo dejado de lado por el panteón oficial, con lo desechado por el progreso y lo oculto para los vencedores. Lo que él sabe sobre el vencido (un ser enigmático de su propia sangre), asciende a la categoría de secreto. La historia como un secreto de familia que solo se puede contar desde adentro.

El Mansilla que aparece en esta causerie viste a la francesa, y le cuesta ser reconocido como compatriota por quienes lo reciben, a tal punto que una fila de curiosos lo sigue hasta su casa. Sin embargo, él declarará que no ha caído en el vicio de la impostación y que sigue siendo "potro americano hasta la médula de los huesos" (L. Mansilla, Entre-Nos 94). Cómo resolver la antinomia "civilización/barbarie", cómo ser un criollo cosmopolita, arraigado en un espacio nativo y también un nómade o un viajero del ancho mundo: esa cuestión se vuelve un eje vital, no solo para Lucio, sino para su hermana Eduarda. Pero quizá su verdadera pertenencia es el entrelugar (Figueiredo 126-7) de las culturas, más allá de las polarizaciones, en una identidad compleja y mestiza. $\mathrm{O}$ el corredor, donde se está y no se está, donde se transita, pero no se duerme, y en cuyos extremos se vislumbran los mundos enfrentados pero intercomunicados: una "condición abierta del ser, que avanza rumbo al oxímoron" (Lojo, "Fronteiras" 308). ${ }^{3}$ Lucio, que murió en París, no sabemos si con aguacero, detenido por su mala salud en el último impulso de retorno, vivió en el corredor. Y también fue un desplazado itinerante en otro sentido, el de la escena política, marcado por su origen federal rosista y por sus posiciones excéntricas. Aun dentro de las facciones que abrazó en distintos momentos de su vida, desde el sarmientismo al roquismo y al juarismo, en sus actitudes y discursos siempre sonaron notas discordantes. Sus "retratos y recuerdos" (1894) muestran los puntos endebles, cuestionables, de los próceres o aspirantes a serlo, y los lados fascinadores del héroe maldito.

Esa mirada oblicua de un personaje cuyo territorio fue el intersticio, la frontera entre los mundos, me marcó la dirección de ingreso a nuestro patrimonio narrativo, quizá porque también el corredor era mi lugar y porque la historia había colocado a mis padres (también sobrevivientes de una guerra civil) del lado de los vencidos. Así fue como los Mansilla-Rosas se convirtieron, de algún modo, en mi familia sustituta sobre suelo argentino y en los proveedores de las notas al pie, de los comentarios al margen, que daban la medida de los matices en el relato patrio y restauraban lo excluido por las versiones simplificadoras.

3 "O corredor não permite o descanso, o estático, a tranquilidade dos esencialismos. [...] Contudo, em sua rica ambivalência, postula uma condição aberta do ser, avança rumo ao oximoro, derrota o pensamento binário, propicia a coincidencia dos opostos" (Lojo, "Fronteiras" 308). 


\section{Los misterios del siglo XIX}

Después de haber concluido mi tesis doctoral sobre Ernesto Sábato, en 1987, abordé formalmente el estudio de nuestra narrativa del siglo XIX. Mis primeras indagaciones (Lojo, La 'barbarie') giraban en torno a las paradojas de la antinomia civilización/barbarie, y en particular sobre los procesos de seducción que, desde el término negativamente valorado (la barbarie), afectan al positivo (la civilización), desestabilizándolo y descentrándolo, en algunos textos canónicos del período: Facundo, El matadero, Amalia y Una excursión a los indios ranqueles. Rodolfo Kusch (Seducción y América) habló de fagocitación, al referirse a la erosión interna, al devoramiento visceral que las culturas originarias vencidas practican sobre la cultura dominante. Podríamos decir que en los textos fundadores de Sarmiento, Echeverría y Mármol, lo bárbaro se reinstala en un gesto de usurpación simbólica y toma por asalto la programática explícita del relato, para activar mecanismos de ambivalencia y de polisemia desde los personajes y espacios protagónicos. En el reverso de la negatividad bárbara se despliegan, así, la fascinación y la identificación, ya fuere vergonzantes o declaradas: "pues si solevantáis un poco las solapas del frac con que el argentino se disfraza, hallaréis siempre el gaucho más o menos civilizado, pero siempre el gaucho" (Sarmiento, Facundo 177). La mitificación (Sarmiento), la modulación de lo siniestro como fuerza de atracción vertiginosa (Mármol), la introyección de lo bárbaro como acting out (Echeverría, en la "muerte de rabia" del joven unitario) son algunas de las derivas posibles del sentido en este proceso.

En Una excursión a los indios ranqueles hay más bien apropiación consentida que usurpación simbólica. Se recupera la llamada barbarie como el espacio natural y real de la vida, donde puede erigirse una cultura más acorde con las demandas auténticas de la condición humana. El mito y lo siniestro dejan lugar aquí a un "realismo" que ejerce la mayor parte del tiempo - sin idealizaciones ni degradaciones - una capacidad de observación antropológica avant la lettre. Momentos líricos y oníricos matizan el arte del retrato y de la escucha en el que el autor descuella.

Volver a Mansilla me abrió dos caminos complementarios. O, mejor aún: un corredor, si se quiere, en el tiempo. Por un lado, se veía el siglo XIX; por el otro, el XX. Desde el siglo XX, el extravagante coronel de capa colorada me parecía un profeta en varios sentidos. Miraba y escribía como un antropólogo contemporáneo, cuando la antropología estaba apenas en sus umbrales y estos eran darwinianos y positivistas. Al menos en ese momento clave de su vida, está dispuesto a declarar que los argentinos (empezando por él) también son indios y que los indios son argentinos. Una verdad oculta que se guardó como secreto de 
guerra entre vencedores y vencidos, y que tarda en salir a luz, aun en el día de hoy (Salomón Tarquini), hundida como un fósil de la Edad de Piedra en la trastienda del imaginario oficial de la nación. Con cautela y sin chauvinismo previene sobre las dificultades del proceso inmigratorio aluvional, y alerta, mucho antes que Ortega y Gasset, o Martínez Estrada o Murena, sobre el peligro de una república reducida a factoría. Por su intuición anticipatoria, por alguna de sus defecciones posteriores y por el filón que representaba su vida y obra para el papel estelar de cualquier novela, empecé a pensarlo como personaje protagónico de una propia que sería después, La pasión de los nómades. Una historia de tránsitos y corredores, en la que Mansilla, vuelto temporariamente a la vida y a su viejo camino de los ranqueles, contemplará con sentimientos encontrados de asombro y decepción la Argentina de nuestros últimos noventa, colocada en el falso umbral del primer mundo. La imagen de Lucio V., testigo de las postrimerías del siglo XX, a la vez juez y parte del mundo que a gusto y a disgusto contribuyó a erigir, estuvo al principio y al fin de este libro con múltiples encrucijadas.

Mirándolo en su propio siglo, Lucio Victorio nos introduce en lo que llamaré, no sin intención irónica, los misterios decimonónicos. Lejos está de Mansilla la visión maniquea del folletinista Eugenio Sue, autor de Los misterios de París (1842-1843), cuyo título a su vez parafrasea a Juana Manso en su novela Los misterios del Plata (1846). Mucho más cerca del maniqueísmo, la perspectiva de Manso, desde la militancia antirrosista, se propone mostrar los horrores, ocultos para la civilización, de la tiranía de Rosas, así como la inocencia de sus víctimas.

Pero justamente porque no es maniqueo, el panorama social que presenta Mansilla es tanto más misterioso. Por un lado, como ya señalé, en sus causeries, en sus Memorias, también en sus Retratos y recuerdos, ilumina el lado oscuro y privado de la historia pública y sus grandes personajes, uno de los cuales es su tío Juan Manuel, al que se muestra, sobre todo en la biografía Rozas, como un ser que excede las visiones recortadas, tanto de sus acérrimos partidarios como de sus implacables detractores. También nos revela otros misterios: la perspectiva de los múltiples seres anónimos, ocultos e ignorados, los que están al margen y al borde, en el límite exterior de la civilización. De esas historias está poblada Una excursión a los indios ranqueles.

Ambos, Mansilla y Sue, exhiben el friso de los excluidos y autoexcluidos de la sociedad hegemónica (Martínez). Pero en Mansilla esos excluidos y exiliados no están en la ciudad (Buenos Aires o París), sino en la frontera y en la Tierra Adentro. Se desplaza así del territorio canónico por excelencia de la literatura argentina (identificada con la región rioplatense y su núcleo porteño) hacia el centro geográfico del país, por donde en ese momento pasaba la frontera sur 
con las comunidades aborígenes. En ese otro centro: la pampa seca, se despliega una nueva topología (positiva) de la "barbarie", que se contrapone, como fuerza regeneradora (por el juego, la libertad en el seno de la naturaleza, el retorno a una vida comunitaria primigenia), con la corrupción, la suciedad y el egoísmo de las ciudades. Algo no tan lejano, después de todo, de la casa de campo donde el noble Rodolfo (en la novela de Sue) lleva, para rehabilitarlos, a los elementos humanos susceptibles de recuperación, sacándolos de las calles oscuras y tortuosas de la Cité (una descripción comparable a la que el propio Mansilla hace en Ranqueles... sobre la ciudad corrupta). ${ }^{4}$ La influencia de Rousseau, del romanticismo, del fourierismo, se deja sentir en ambos. En Mansilla se liga directamente con una reivindicación de la supuesta "barbarie" y con una ampliación del mapa etnocultural argentino, con elementos que no están ni siquiera adentro, en los "bajos fondos", sino "afuera", en un espacio ajeno para los ciudadanos de las metrópolis (o grandes aldeas) de la época. Sobre todo, para Buenos Aires.

Los "misterios del siglo XIX" que revela a sus contemporáneos en Una excursión a los indios ranqueles: gauchos perseguidos, tránsfugas políticos, cautivas, indios, misioneros, soldados de fortín, son novedosos para la literatura y para la crítica literaria, no porque estas figuras no hubieran aparecido nunca en textos canónicos, sino porque Mansilla logra reponerlos desde sus voces propias con una mirada curiosa que nos muestra un mundo coral y plural, más allá de las rígidas oposiciones.

\section{"Salvajes" no tan ajenos}

Como pude comprobar en mi propia "excursión" de 1992, siguiendo los pasos de Mansilla en su camino hacia las tolderías ranqueles de 1870, la presencia activa y la huella étnica de los aborígenes del siglo XIX en la historia, la sociedad y la política nacionales habían sido borradas por una amnesia programática. Los vencedores de una guerra que se había hecho, según las ideas-fuerza de aquel tiempo, contra el "salvaje" (léase, desprovisto de toda cultura realmente humana) para poblar el "desierto" (Navarro Floria, "El salvaje" y "El desierto"), proponían el territorio a ocupar como tábula rasa, lista para ser colonizada por los contingentes del progreso. Se expande en el imaginario colectivo la idea de que la derrota ha exterminado físicamente a los indios. Sin embargo, puede decirse que los hizo invisibles, para los otros y para sí mismos. Antes que el exterminio físico, aunque desde luego también lo hubo, primó la desaparición simbólica, el borramiento de

4 No está de más señalar que la primera de las dos obras de teatro del autor argentino, Attar Gull (1864), se basa en la novela homónima de Sue. 
toda alteridad, promovida por un proyecto político de sociedad homogénea, de cultura eurocéntrica (Quijada). Por otro lado, la carga de discriminación que la condición de "ser indio" (Daireaux) traía implícita, hizo que los mismos vencidos terminaran por asumir, como demostró Isabel Hernández en su estudio sobre la comunidad de los coliqueo, en Los Toldos, una identidad enmascarada. La Argentina como nación ${ }^{5}$ arrastra una identidad mutilada, al negar de esa manera parte de su proceso constructivo. Las anécdotas de mi viaje del 1992, que luego pasaron a la novela, muestran de manera elocuente este proceso de conquista de la memoria (Navarro Floria, "La conquista"): los lugareños confundían a Mansilla con el historiador Carlos Mayol Laferrere, que había reconstruido la expedición mansillesca en la década de los ochenta. Y el mayordomo de la estancia situada en Leubucó, en el solar donde se habían alzado las tolderías de Mariano Rosas, profesaba un escepticismo absoluto sobre la misma preexistencia de los ranqueles en esos parajes.

Hacer del camino de Mansilla mi objeto de (re)escritura me reinstaló en esa memoria borrada desde varios ángulos: el geográfico inmediato, mapas en mano y a bordo de un viejo Mercedes Benz modelo 1953; el de la conjetura ficcional, en un cruce de géneros, materializado en la novela La pasión de los nómades ${ }^{6}$-relato de viaje, road movie y fantasy histórico - y el de la investigación académica, que sigue abierta, porque hay un verdadero acervo de relatos, cartas y testimonios en proceso de recuperación que esperan el abordaje de la ecdótica y de la crítica literaria. Antropólogos e historiadores, académicos y autodidactas, han ido exhumando estas piezas arrinconadas en archivos y museos. El primer atisbo de ese tesoro lo tuve al conocer a Carlos Mayol Laferrère, en 1991, cuando lo visité en el Archivo Histórico Municipal de Río Cuarto, en busca de guía por ese camino de Mansilla que él había recorrido diez años antes, a la cabeza de un contingente de excursionistas a caballo. No solo me traspasó sus cartas de saber geográfico, sino que me mostró otro mapa de historias entrelazadas y voces contrapuestas.

El investigador riocuartense, uno de los más destacados expertos en la historia de la frontera sur, ya había empezado a escribir, por aquel entonces, un estudio que se proponía seguir, jornada por jornada, la excursión de Mansilla, incorporando no solo toda una trama de referencias históricas y geográficas, sino otros relatos nunca publicados, como los de los franciscanos que lo acompañaron. Gracias a él pude

5 Desde el lado de la historiografía académica, irían apareciendo en los años noventa cada vez más trabajos sobre los aborígenes como actores imprescindibles en la formación de la Argentina actual y, en nuestros días, comienzan a verse estudios sobre la "resiliencia" de estas comunidades dentro de nuestra sociedad contemporánea.

6 Publicada por primera vez en 1994. 
acceder a toda la documentación inédita ya acumulada, que fue creciendo durante los veinte años en que esta obra continuó su lento proceso. Apareció por fin, en 2012, con el título Tras las huellas de Mansilla. Contexto histórico y aportes críticos a una excursión a los indios ranqueles y tuve la alegría de prologarla. En este monumental trabajo, Mayol entreteje el texto de la obra con archivos periodísticos, con el informe militar del propio Mansilla, y con relaciones y apuntes de tres sacerdotes involucrados en este viaje: los franciscanos Marcos Donati y Moisés Álvarez y el dominico Vicente Burela, que a su vez eleva su testimonio ante el Ministro Avellaneda. Los comentarios del autor conectan todos los textos, comparan afirmaciones divergentes, aclaran puntos oscuros y añaden informaciones y explicaciones.

Dentro del aporte riocuartense hay que considerar también una compilación de importancia, que ya había aparecido en 1995: Cartas de frontera. Los documentos del conflicto interétnico, realizada por Marcela Tamagnini. Se trata de una selección de 595 documentos, de entre 1860 y 1880, del Archivo del Convento de San Francisco de Río Cuarto, dividido en "Cartas indígenas", "Cartas de sacerdotes" y "Cartas civiles", de muy variados remitentes.

Si en el futuro aparece una edición crítica o crítico-genética de Una excursión a los indios ranqueles (hasta ahora hay solo buenas ediciones eruditas, anotadas y prologadas) seguramente deberá tener en cuenta (además de los originales de La Tribuna, donde por primera vez se publicó la obra, en entregas de folletín), estos textos paralelos y esta documentación histórica que proporcionan una perspectiva verdaderamente poliédrica.

Nuestras investigaciones más recientes han aportado un eslabón perdido de la cadena genética que conduce a Una excursión a los indios ranqueles: los manuscritos de un diario de viaje en dos formatos: un borrador más extenso y una versión vertical más breve, puesta en limpio, que registra las impresiones de su viaje oriental, el de "Los siete platos de arroz con leche". Se trata "del primer relato de viajes de nuestra literatura cuyo destino es el Oriente" (L. Mansilla, Diario 38). Su aparición fortuita, en el desván de la casa materna de su tataranieto, Luis Bollaert, y la generosidad de este descendiente, nos dieron la oportunidad de publicarlos por primera vez. La edición del Diario de viaje a Oriente y otras crónicas del viaje oriental constituyó uno de los objetivos del Proyecto Plurinanual de Investigación 5878: "Los hermanos Mansilla: edición y crítica de textos inéditos u olvidados", del cual fui investigadora responsable.

7 Parte de este material es hoy accesible en la web: http://www.mapuche.info/wps_pdf/tamagnini031101.pdf 
Estas páginas iniciales, cuando Lucio V. Mansilla, de dieciocho años, era apenas un aprendiz de lector y de escritor, deslumbrado y perplejo ante el mundo de las antípodas que le había tocado en suerte descubrir, son de algún modo la "piedra roseta" para abordar la singularidad de la "mirada invertida" que se despliega en Ranqueles. Quizá pudo considerar que la teoría de la superioridad de ciertas razas y pueblos por sobre otros no es sino una excusa para justificar el despotismo, porque él mismo había sido mirado como un salvaje en la India por los representantes de las potencias imperiales de la época.

Hay tres escenas en particular, dignas de marcarse en este Diario. En las dos primeras, Lucio se muestra a los ingleses disfrazado de "paisano gaucho". Trabaja en suma, de gaucho for export, para ofrecer un espectáculo pintoresco. La primera vez, esto ocurre a pedido del anfitrión, satisfecho con placer por un huésped ingenuo: "Ayer recibi una invitación, de Mr. Barstow el gefe de la Casa de Barstow Wihtnay \& $\mathrm{C}^{\mathrm{o}}$ para ir á almorzar á su casa en trage de gaucho y hoy lo he pasado con él y otros tres mui divertido - El trage de nuestros paisanos les ha agradado mucho" (L. Mansilla, Diario 197).

La siguiente tiene lugar en el "baile de fantasía" de fin de año, que otro personaje, el coronel Warren, ofrece en su casa. Repite el mismo disfraz, incluso con grandes bigotes postizos, pero ya no tiene el mismo eco: "El Coronel Warren estuvo mui político conmigo ni siquiera me presentó á su Sra.; estuve hermosamente fastidiado, hasta las dos de la mañana, pues como no conocia á nadie no pude bailar-" (L. Mansilla, Diario 206).

Va probando así los límites de la "amable cortesanía inglesa" (según dice, cada vez más irónico), en una sociedad fuertemente jerárquica y estratificada, donde las clases bajas colonizadas viven en la miseria servil y los orgullosos ingleses "temen perder en su casta" (L. Mansilla, Diario 206) si se pasean de a pie, y no acostumbran devolver visitas.

Aún sin noticias de los suyos (y ya van seis meses), en el trayecto de Calcuta a Madrás, la mirada de un comerciante inglés le presenta una irreconocible imagen de sí mismo (y de los argentinos), como el "otro" absoluto, exótico y primitivo: "hoi he tenido con un Ingles una combersacion mui interesante respecto á mi pais; tienen de él la mas pobre idea; creen que somos salvages [subrayado en el original], y les sorprende cuando me oyen hablar frances y que digo lo he aprendido en Buenos Aires" (L. Mansilla, Diario 229).

Sí: se puede estar en el lugar del que considerábamos "el otro", el "salvaje": salvaje unitario, salvaje ranquel. Quizá, después de todo y como nosotros mismos, no tan salvaje. Es este uno de los grandes aprendizajes del joven Lucio, exiliado de los suyos en nave de oro (doscientas mil libras esterlinas iban a bordo 
para respaldarlo), pero exiliado al fin, muy lejos de los afectos y también de la élite donde podía reconocerse. Los ecos de este extrañamiento siguen resonando en Una excursión a los indios ranqueles.

\section{Eduarda Mansilla, la adelantada}

A fines de los años ochenta del siglo pasado, las memorias y alguna causerie de Lucio Victorio me presentaron a su hermana Eduarda, que era, según sus palabras, "monísima, inteligente, lista, donosa" (L. Mansilla, Mis memorias 123), muy dotada para la música y los idiomas y, además, una niña mucho menos crédula y asustadiza que su hermano mayor, siempre aterrorizado, a la hora de dormir, por los cuentos de ánimas en pena. ${ }^{8}$

Algo tan inusual como una hermana escritora no podía ser desaprovechado. Eduarda, confidente, compañera de aventuras literarias, tenía que aparecer en la novela La pasión de los nómades y, en efecto, así lo hizo. Fantasmal, pero con tirabuzones y vestido de soirée, y algunas interesantes experiencias de ultratumba para contar: "Estuve dando vueltas por Washington, hospedada en la biblioteca del Congreso, aunque ignoro por qué fui a parar a ese sitio. Sería debido a la impresión que me causaron los Estados Unidos cuando Manuel cumplía allí funciones de ministro plenipotenciario. Dudo que te dés idea de las cosas nuevas que he aprendido. También estuve leyendo a las feministas" (Lojo, Pasión 1899o). Así es como Eduarda se entera, entre otras cosas, de que mujeres y minorías étnicas se parecen, porque ambas fueron dominadas y colonizadas. Pero lo que más la perturba es saber que en la Argentina casi no se conserva un ejemplar de Pablo ou la vie dans les Pampas (1869), su magnum opus, y espera que Rosaura dos Carballos, el hada que ha logrado reencarnar a Lucio, le sirva de ayuda para recuperar el baúl inglés donde quedaron cientos de sus críticas periodísticas, nouvelles y piezas teatrales. Lamentablemente, ni siquiera la magia gallega de Rosaura ha podido hasta hoy rescatar ese tesoro perdido.

No obstante, este último cuarto de siglo ha sido pródigo en investigaciones $\mathrm{y}$ fecundos hallazgos, tanto en lo que se refiere puntualmente a Eduarda como en lo que hace a las escritoras decimonónicas en su conjunto, y ello compensan un largo periodo de silencio que abarca desde el capítulo pionero que Ricardo Rojas dedica a las novelistas del XIX en el volumen VII de su Historia de la literatura

8 Los contaban el tío Tomás y la negra María (Mansilla 1954, 82), que aún debían ser formalmente esclavos, aunque se había decretado en 1813 la "libertad de vientres". Mientras que los servidores negros son descritos con simpatía y espíritu vindicador en la narrativa de Eduarda, no sucede lo mismo en los escritos de Lucio. Quizás no sean ajenas a esto sus contrastantes reacciones infantiles ante los relatos nocturnos... 
argentina (1. ${ }^{\mathrm{a}}$ edición de 1922), pasando por escasas (y, a menudo, despectivas) menciones en historias sucesivas, hasta desembocar en los estudios precursores de Lily Sosa de Newton ${ }^{9}$ y Néstor Tomás Auza. Ya en el umbral de los años noventa del siglo XX, era muy poco aún lo que se había trabajado en la Argentina sobre nuestras primeras escritoras. Los women studies, asociados con los cultural studies, en los Estados Unidos, abrieron una senda de interés en las antepasadas literarias. Aparecieron libros individuales dedicados a las autoras del Río de la Plata, como los de Bonnie Frederick (Wily) o Francine Masiello (Between), así como antologías, preparadas por estas mismas críticas (Frederick, 1993; Masiello, La Mujer), ambas publicadas en Argentina por Lea Fletcher en la editorial Feminaria. ${ }^{10}$

De entre las autoras decimonónicas, la primera en atraer estudios monográficos más extensos fue Juana Manuela Gorriti. La novela pionera de Marta Mercader (Fuanamanuela, mucha mujer, 1980) instala en la consideración del público general su imagen de escritora que, en verdad, nunca había desaparecido del todo de las historias de la literatura (Rojas, Arrieta, Centro Editor de América Latina), después de haber gozado, en vida, de una difusión relativamente vasta y de un prestigio que se materializó en la publicación de sus Obras completas. ${ }^{11} \mathrm{El}$ ajuar de la patria (1993, compilado por Cristina Iglesia) y El taller de la escritora, de Graciela Batticuore (El taller), a ella dedicados, dan testimonio de ese interés que alcanzó un hito en la tesis doctoral de Hebe B. Molina (La narrativa). Lidia Lewkowicz publicó una biografía y estudio crítico de la obra de Juana Manso, y Élida Lois emprendió, para la Colección Archivos, una edición genética de Los misterios del Plata, aún en proceso.

Llegada la última década del siglo Xx, la mayoría de los textos de Eduarda Mansilla no se había reeditado, salvo El médico de San Luis, y este siempre en

9 La autora había publicado ediciones anteriores de esta obra, que comenzó a escribir a partir de la buena acogida obtenida por Las argentinas de ayer a hoy.

10 Cabe agregar la de narradoras compilada por Sosa de Newton.

11 Las Obras estaban precedidas de una Palma Literaria y Artística en su homenaje, que le ofrecieron personalidades del ámbito social, político e intelectual de su tiempo (como Bartolomé Mitre y Juan María Gutiérrez). Fueron reeditadas, tomando como base sus facsímiles, por la Fundación del Banco del Noroeste Cooperativo (Salta), al cuidado de Alicia Martorell. Dicha edición comprende seis tomos, que aparecieron entre 1992 y 1999; la Palma puede leerse en el primer tomo. La circulación y puesta en valor académico de la obra de Gorriti se ha incrementado en los últimos años. Podemos mencionar la edición bilingüe (castellano/italiano) de Un oasis en la vida (2010), a cargo de la especialista Ilaria Magnani, autora también de la Introducción, y la edición erudita de La tierra natal (2013), a cargo de la especialista Leonor Fleming. La Biblioteca del Norte (auspiciada por la Secretaría de Cultura de la Provincia de Salta) acaba de lanzar, con este tomo, una nueva publicación, esta vez académica, de las Obras completas de la autora salteña. 
ediciones no académicas. En 1996 aparece Recuerdos de viaje, en una edición familiar de rescate, sin notas ni crítica textual, con una semblanza introductoria realizada por la historiadora María Sáenz Quesada y en 1999 la editorial argentina Confluencia publica una traducción (debida a Alicia Chiesa) de Pablo, ou la vie dans les Pampas, destinada a todo público. Hubo que llegar al siglo XXI para empezar a contar con ediciones científicas. ${ }^{12}$ La primera de carácter realmente erudito, en una colección especializada (TECI, de Iberoamericana/Vervuert) fue la de Lucía Miranda realizada por nuestro equipo (Lojo, Una mujer). Unos meses después, a fines de ese mismo año, María Gabriela Mizraje publicó la traducción de Pablo... (hecha por Lucio V. Mansilla para La Tribuna) en una edición que no posee notas, ni cotejos críticos de variantes hoja por hoja, pero cuenta con un importante estudio preliminar donde sí estudia variantes y compara la traducción de Lucio V. con el original francés. ${ }^{13}$

Todavía uno de los "misterios" más inquietantes del siglo XIX sigue siendo Eduarda, como personaje tentador para cualquier novelista y, sin duda, como literata. Sobran las razones. Adelantada y fundadora, vanguardista en el sentido etimológico del término, abre caminos en muchos campos. Se halla entre las primeras autoras argentinas de relatos de viaje, y es la segunda en publicar un libro de este género. ${ }^{14}$ Aunque siempre se señala a Lucio como el gran precursor del Martín Fierro, ella, y no su hermano, introduce en la literatura el tema del gaucho perseguido (Lojo, "El imaginario" y "Naturaleza"; Molina, Como 334-7) y la vida posible de un blanco entre los indios, ya desde El médico de San Luis (1860). Ella es la primera en postular el episodio de Lucía Miranda (de la crónica La Argentina manuscrita, 1612) como piedra fundadora de una futura nación mestiza, simbolizada por la pareja interétnica de Alejo y Anté. Y la que coloca a los luego invisibilizados afroargentinos en espacios protagónicos de reivindicación (el tío Antonio, de sus Cuentos, o Rosa, la nodriza de Dolores en Pablo...). También está en la avanzada de las précieuses argentinas (Alvarado-Larroucau), en cuanto autora de nuestra primera novela escrita en francés y elogiada por Víc-

12 En 2006, la edición de Spicer Escalante de Recuerdos de viaje (Stockcero) representa un avance, pues se trata de una edición anotada y con el prólogo de un estudioso.

13 La investigadora ya lo había hecho en otro trabajo ("Eduarda Mansilla"); Batticuore (La mujer), había comentado también con pormenor la traducción de Lucio. Otros textos de Eduarda Mansilla (periodísticos y narrativos) han obtenido ediciones modernas sólo en antologías de escritoras como las arriba citadas u otras posteriores (Arambel Guiñazú).

14 La investigación en curso de Norma Alloatti señala como la primera argentina en publicar un relato de viaje a Francisca Espínola, con su Memoria del viage a Francia de una argentina de la provincia de Buenos Aires, publicada en Marsella en 1850. 
tor Hugo. Es, como lo señala Hebe Molina, "la escritora más ilustrada del siglo XIX" (Molina, citada en E. Mansilla, Cuentos 9). ${ }^{15}$

Eduarda inaugura la literatura infantil en nuestro país con sus Cuentos (1880), una colección de relatos que se propone, dice, "producir en español, lo que creo no existe aún original en ese idioma: es decir, el género literario de Andersen" (E. Mansilla, Cuentos 93). Con ese libro, vuelto a publicar por primera vez en la cuidada edición crítica de Molina, iniciamos por nuestra parte algo que tampoco existía entre nosotros: la colección EALA, en la editorial Corregidor, dedicada exclusivamente a ediciones eruditas, críticas y crítico-genéticas de literatura argentina, bajo la dirección general de quien les habla, y la codirección de Jorge Bracamonte (Conicet-UNC). Este primer volumen de cuentos para niños, saludado por Sarmiento en El Nacional (Lojo, "Sarmiento" 125-6), debería figurar en los currículos escolares, y no tendría que faltar en ninguna biblioteca pública. Sin embargo, hasta la nueva edición de 2011 era una obra poco menos que inhallable y, todavía hoy, sigue sin difundirse. La editora destaca su originalidad frente a los modelos europeos vigentes. No apela a la narrativa tradicional y maravillosa de diversos orígenes: inventa nuevas anécdotas y situaciones en un contexto actual y cotidiano; no los divide, por género, en cuentos "rosas" y "azules" (como Laboulaye o la condesa de Ségur) y, a pesar de que se trata de narraciones para niños, en que la mirada narradora suele identificarse con los ojos infantiles, su prosa se sigue impregnando de referencias culturales (a obras de arte musicales y pictóricas, lecturas, hechos históricos, geografías diversas), que la confirman en su peculiar condición de autora erudita, aun en este género destinado a los menores.

Sus Creaciones (1883), que pronto vuelven a publicarse también en EALA, en la edición crítica de Jimena Néspolo, se hallan en otro umbral: el del "gótico rioplatense", una "poética de la imaginación y la desmesura", la llama Néspolo, que reconocerá sucesoras contemporáneas como la inquietante Silvina Ocampo. Uno de estos relatos: "El ramito de romero", preanuncia a Borges, tanto el de "El Aleph" (hecho apuntado por María Gabriela Mizraje) como -añade la editora- el del libro Atlas. También, observo, anticipa en su descenso a las sombras de la morgue (submundo dentro de la ciudad donde se despliegan visiones

15 La fama de esa ilustración debió de llegar a los oídos de Federico Carlos, príncipe de Prusia, que luego se convirtió en el káiser Guillermo I. A poco de publicarse Pablo... en la revista L'Artiste, de París - cuenta Daniel García Mansilla (87) - el príncipe, como mecenas de las letras, le escribió para ofrecerle una posición en su corte, que Eduarda declinó porque su marido, el diplomático Manuel Rafael García Aguirre, acababa de ser nombrado ministro plenipotenciario en Estados Unidos. 
portentosas del más allá y del destino individual y colectivo) las experiencias de otro aventurero literario del siglo Xx, Fernando Vidal Olmos, en el Informe sobre ciegos, de Ernesto Sábato (Lojo, "El ramito"” 36-7).

La prensa es otro terreno en el cual Eduarda descuella y precede. Si bien las escritoras habían incursionado hacía tiempo en el periodismo (La Aljaba, de 1830, es el primer periódico femenino de Buenos Aires), no era común que lo hicieran fuera de los circuitos de mujeres (aunque las revistas femeninas sí contaran con colaboradores masculinos) y para ellas. Eduarda lo logra, después de una larga lucha. Como dice Sarmiento: "ha pugnado diez años por abrirse las puertas cerradas a la mujer, por entrar como cualquier cronista o reporter en el cielo reservado a los escogidos (machos), hasta que al fin ha obtenido un boleto de entrada, a su riesgo y peligro, como le sucedió a Juana Manso, a quien hicieron morir a alfilerazos porque estaba obesa y se ocupaba de educación" $(376) \cdot{ }^{16}$ No es la única en lograrlo, pero sí es la autora que alcanza una presencia más sostenida y asidua en medios de prensa que no eran los exclusivamente "femeninos", como La Nación, El Nacional, La Gaceta Musical, con artículos de opinión sobre diversos temas de actualidad, además del arte y la moda. Como parte de la investigación que estamos desarrollando en el PIP 0286, se publicará en breve la edición crítica de sus escritos periodísticos completos, a cargo de Marina Guidotti, de la Universidad del Salvador, junto a todas las noticias de Eduarda y sobre ella que aparecieron en la prensa periódica. Sin embargo, constata Guidotti, aún es una asignatura pendiente la debida inclusión de Eduarda en historias generales del periodismo, fuera de los libros especializados en mujeres. ${ }^{17}$

Los más de cinco años (entre 1879 y $1885^{18}$ ) que la escritora pasa en Buenos Aires acompañada solo por su hijo menor Carlitos, ${ }^{19}$ mientras sus demás descen-

16 "Una sobrina de su tío. Correspondencia de Zárate" (Sarmiento, Obras 376).

17 Por ejemplo, no hay mención a ella en la Historia de revistas argentinas $(1997,1999$ y 2001$) \mathrm{ni}$ en la De Marco.

18 No hemos podido establecer aún con exactitud su fecha de retorno a Europa. Por la noticia aparecida en agosto en El Nacional se sabe que en agosto de 1885 todavía se hallaba en Buenos Aires, aquejada de una enfermedad de la vista (año XXXIV, número 11.708 Buenos Aires, Sábado 8 de agosto de 1885 Director Samuel Alberú,p.1, col. 7). También se sabe que en 1886 ya se encontraba en Europa, por otra noticia aparecida el 20 de mayo de 1886 en El Nacional. Debo estos datos a Marina Guidotti.

19 Este dato se ha confirmado no hace mucho. La creencia antes extendida era que Eduarda había viajado sola. Pero las cartas de Carlitos García Mansilla dirigidas a su padre desde Buenos Aires y conservadas en el archivo familiar de Miguel Herráiz (bisnieto de Eduarda que me cedió gentilmente copias de estas) prueban lo contrario. Hebe Molina (en Mansilla, Cuentos 21, n. 18) se refiere también a un artículo de su hermano Lucio V., aparecido en El Nacional (28.04.1879) donde se refiere al retrato de Eduarda y de su hijo menor pintado por un artista. 
dientes y su marido continúan en Europa, constituyen su etapa de producción literaria más intensa. Es también en esta época de actividad incansable cuando reedita sus obras juveniles y publica otras nuevas. ${ }^{20}$

\section{La razón de las mujeres}

Eslabón perdido y llave maestra de tantas cadenas literarias, esta escritora sobre la que mucho queda por decir aún nos introduce en el reverso de la épica, donde rige la razón de las mujeres. Aunque no es la primera ni la única en este campo, lo hace con la mayor intensidad y complejidad de matices y de forma regular y sistemática desde sus libros iniciales.

Que las mujeres sean "el corazón del género humano", como se señala en Lucía Miranda (211), asintiendo a una cita de autoridad, no les impide tener razón: tener la razón en un mundo gobernado por la ley de la violencia que condena a los hombres a matarse los unos a los otros e invierte el orden natural y hace que las madres sepulten a sus hijos. En esta misma novela, la función educadora que asume la protagonista, puente entre mundos y culturas, se destaca por sobre la función épica que insensatamente cumplen los varones: " ¿Esta es la guerra? ¡Qué horrible cuadro hacéis de esos desgraciados perseguidos sin piedad! [....] ¡Dura ley, que convierte en terrible y desapiadado, al mejor de los hombres! ¡Qué suerte, que las mujeres, estemos siempre libres de semejantes espectáculos! ¡Oh, entónces los héroes que tanto admiramos, nos causarian horror!" (E. Mansilla, 294).

Su novela de ese mismo año, El médico de San Luis, propone un doble alegato: a favor del gaucho, sujeto de toda injusticia, y en pro de una autoridad social que esté personificada en las madres y ejercida por ellas. No vacila incluso en declarar abiertamente la "superioridad femenina" en el campo intelectual de la población promedio, lo cual, unido a una mayor conciencia de las mujeres en cuanto al valor de la vida que ellas mismas engendran, debiera habilitarlas para emprender, a partir del ámbito doméstico, una verdadera reforma de la sociedad (Lojo, Naturaleza 244-5) y sus falsos valores.

Eduarda Mansilla es también una pionera en la composición musical, como autora de canciones originales y de inspiración americana (Veniard 24-42). Tiene asimismo relevancia entre las escasas dramaturgas que existen por entonces. La primera obra teatral que compuso y estrenó (en París, 1873) fue "Similia Similibus", luego incluida en el volumen Creaciones (1883). A ella se le sumaron La marquesa de Altamira (estrenada en 1881) y el drama Los Carpani, cuyo estreno (el 1 de junio) comentó La Gaceta Musical el 3 de junio de 1883, año X, n. ${ }^{\circ}$. Del resto de su producción dramática solo han quedado referencias: de 1883, Ajenas culpas; Elena y dos dramas en prosa El Testamento y María. En 1901 se anunciaba La batalla de Santa Rosa, obra que, al parecer, no fue representada (Guidotti, Marina. En prensa en Diccionario de teatro hispanoamericano, Marina Gálvez, ed.). 
La "razón de las mujeres" vira hacia la locura cuando la amenaza la ley de la épica, el mandato del héroe. No se trata únicamente de ese "secreto gótico" del que se han ocupado ya clásicos estudios feministas como The Mad Woman in the Attic (Gilbert y Gubar): la loca o enloquecida por la subordinación social y la represión sexual (y la de toda energía creadora), que se esconde tras el "ángel del hogar" en el mundo victoriano. Aunque esos elementos, sin duda,juegan (un caso bastante claro en este sentido es el cuento justamente titulado "La loca", de Creaciones); aun allí, el desencadenante fundamental de la locura femenina es la violencia fratricida de los varones. Esa violencia condena a las mujeres a múltiples encierros y cautiverios, y a ellos, a morir como parias en la intemperie de un honor mal entendido. Marginadas por su escasa o nula instrucción, que les impide adquirir plena conciencia de sí mismas; privadas de los hijos que constituyen, en un mundo patriarcal, el único fin y sentido de sus vidas, las madres enloquecen, como Micaela o Kate.

Eduarda, madre fecunda que no vio morir a ninguno de los suyos y que buscó en la ilustración y la creación la libertad y la autonomía, sin embargo, nos deja el regusto de un destino perturbado, incompleto. Falleció a los cincuenta y siete años, víctima de una enfermedad cardiaca, pero su mala salud no llega a justificar del todo el silencio de su última etapa, y menos aún el paradójico pedido dirigido a sus descendientes, de que no volviesen a editar sus obras por cuya difusión tanto había luchado. ${ }^{21}$ Esas y otras contradicciones que hacen de Eduarda un símbolo de la vida creadora femenina y de sus dificultades, incluso hoy día, me motivaron a escribir la novela Una mujer de fin de siglo (1. ${ }^{\text {a }}$ ed. 1999), que la tiene como personaje central. Las preguntas se disparan en torno a ese último mandato: ¿ise trató de un rasgo admirable de humildad cristiana, como prefiere sugerir su hijo Daniel?, ¿una forma de autocastigo, por la ruptura familiar que le había significado su dedicación a la vida literaria durante sus años de independencia en Buenos Aires?, ¿un gesto de despecho y desilusión, como presume Hebe Molina, ante la "chatura poco patriótica que la rodeaba" (Molina, citada en Mansilla, Cuentos 88) y que impidió a sus contemporáneos, y a una larga posteridad, apreciar el valor pionero de sus obras?

En algún momento, tuvo que plantarse ante una alternativa de hierro entre lo público y lo privado, entre ser protagonista o esposa y acompañante, entre la vida artística y la vida familiar, entre el exilio dorado de la diplomacia y el

21 Dice en su testamento: "Se me enterrará con sencillez. No se invitará a nadie, ni se pondrán avisos en diarios. No deseo misas sino una sola en cualquier Iglesia y rezada. Deseo que no se haga nunca reimpresión de mis escritos" (Archivo General de la Nación, Legajo 7081, f. 54. Número de timbre 399986-1 peso-año 1893. En el extremo izquierdo en relieve al agua "Ley de Sellos"). Copia facilitada por el investigador Walter Derbiz. 
retorno a la patria para reconocerse. Las condiciones de su época y de su vida no le permitieron otra cosa. Es, en parte, la misma tragedia de la Nora Helmer de Ibsen, su contemporánea, como apunta un personaje de Una mujer de fin de siglo: "haberse visto forzada a llegar a ese extremo. Haber tenido que desgarrarse para poder sentirse libre, aun a cosa de abandonar a los suyos" (Lojo, 261). O como la propia Eduarda dice en la novela, para poder cumplir "el deber que todo ser humano tiene consigo mismo" (155).

\section{Descubriendo la "biblioteca oculta" del pasado. Géneros y textos marginales, últimas líneas de investigación}

Desde que recibí, como un regalo que cambió mi vida, aquel bonsái de literatura decimonónica, la ampliación del corpus textual y la renovación de los estudios sobre nuestro siglo XIX ha sido extraordinaria. El multifacético panorama sintetizado y anunciado por los hermanos Mansilla está en pleno despliegue. La biblioteca jibarizada se ha convertido en un frondoso bosque de dimensiones naturales, donde crecen todo tipo de árboles y de arbustos, cuelgan las enredaderas y hasta aparece, de cuando en cuando, alguna flor carnívora.

De Ricardo Rojas en adelante, y aun a pesar de criterios esteticistas taxativos que este primer gran historiador sistemático a veces aplica, no puede negarse un interés por la recuperación de lo periférico, lo popular y lo masivo. O de lo raro y también olvidado. Pienso en colecciones de rescate, como "El pasado argentino", que transmigró desde Hachette a Solar-Hachette, y luego a Taurus, variando la denominación, pero que contó siempre con la dirección infatigable y lúcida de Gregorio Weinberg.

Pero el gran auge de las publicaciones de exploración, restitución y rescate, se halla, creo, sobre todo a partir de las décadas de los ochenta y de los noventa del siglo XX. Convergen para explicarlo, a mi entender, varios factores: 1) el renovado interés por nuestra historia, manifiesto en la intensa producción en el campo de la historiografía, tanto la académica como la de divulgación, y asimismo en el retorno a la ficción histórica (línea basal de la novela argentina), en un contexto de globalización asimétrica y crisis interna que exacerba la pregunta por la construcción de la identidad nacional en el tiempo (Lojo, "Las narrativas"). 2) El foco puesto en la "historia desde abajo", la historia de las mujeres y de la vida privada, la microhistoria (Burke). 3) La incidencia creciente de los estudios culturales (Szurmuk y Mckee) y la sociología de la literatura. ${ }^{22} 4$ ) Los estudios

22 Libros como los de Jorge B. Rivera sobre el folletín gauchesco o, ya sobre el siglo XX, el trabajo de Beatriz Sarlo en El imperio de los sentimientos. Narraciones de circulación periódica en 
y los debates sobre poscolonialidad y subalternidad (de Toro y de Toro). 5) La influencia del feminismo académico, que desemboca en la creación de publicaciones especializadas, de institutos de género, y en la convocatoria a jornadas y congresos específicos. Las revistas Feminaria (fundada en 1988) y Mora (fundada en 1995), del Instituto de Estudios de Género de la Universidad de Buenos Aires se constituyeron en importantes órganos de difusión de estas corrientes. En el plano de la divulgación cabe destacar la recién creada colección Las Antiguas. Primeras Escritoras Argentinas, dirigida al lector no especializado. ${ }^{23}$ 6) La puesta en valor de los "géneros del yo" y del "espacio biográfico" (Arfuch), que abarcan memorias, autobiografías, diarios íntimos, testimonios y epistolarios. ${ }^{24}$ 7) El interés, concomitante, en el relato de viaje, las escrituras del viaje y la elaboración de poéticas de estas modalidades narrativas (Prieto, Los viajeros; Carrizo Rueda, Poética y Escrituras; Szurmuk; Duplancic de Elgueta ${ }^{25}$ ). 8) La reafirmación de la ecdótica y el enriquecimiento de la tradición filológica a través de la crítica genética. Cabe mencionar especialmente la investigación temprana de Beatriz Curia con su proyecto Edición y Crítica Textual de Literatura Argentina (ECTLA), que continúa en desarrollo y que ha aportado al corpus de la literatura nacional ediciones críticas de textos desconocidos, entre ellos, los del primer novelista argentino: Miguel Cané padre. También Élida Lois, en la Colección Archivos y actualmente, en su proyecto Edición del archivo documental de f. B. Alberdi, de la Universidad Nacional de San Martín. 9) En la Universidad Nacional de La Plata, por su parte, Graciela Goldchluck y sus colaboradores promueven la archivística como disciplina en expansión. 10) La concepción histórica de las poéticas, apoyada en la teoría de los polisistemas (Even-Zohar 38-48), que abre el campo de

la Argentina (1917-1927) [1ª . ed. 1985], en la línea sociológica, anuncian este interés por las llamadas "producciones menores". Lo mismo que el ya clásico estudio de Adolfo Prieto: $E l$ discurso criollista en la formación de la Argentina moderna.

23 Publicada por la editorial cordobesa Buena Vista, que dirige Daniela MacAuliffe. La colección está a cargo de la escritora Mariana Docampo y se propone dar a leer estas autoras ignotas para la mayoría de los argentinos, en ediciones de bella presentación, cuyos títulos son prologados, cada uno, por una escritora contemporánea. No son paleográficas ni críticas y carecen de notas de tipo académico.

24 La editorial El Elefante Blanco y la colección Memoria Argentina, de Emecé, volvieron a publicar en la década de los noventa muchas obras de esta índole en ediciones destinadas a todo público. En lo que hace a epistolarios, cabe destacar, dentro del campo académico, los novedosos estudios de Cohen Imach y de Galán.

25 La tesis doctoral de María Laura Pérez Gras (miembro del PIP 0286), actualmente en prensa en el Portal Cervantes, desarrolla una poética hasta ahora inédita, del relato de cautiverio, en sus relaciones con el relato de viaje, focalizándose en tres relatos de cautivos en territorio argentino: Santiago Avendaño, Auguste Guinnard y Franklin Bourne. 
estudio hacia una multiplicidad de textos que se habían dejado de lado; pero son vitales para comprender la evolución de los géneros. Tanto en el rescate de los textos como en la formulación de una poética histórica de la novela, el trabajo de Hebe Molina (Como) tiene un papel fundamental. ${ }^{26}$ Y 11) El estudio de la recepción lectora, las historias de la lectura y la profundización de las investigaciones bibliotecológicas, que nos permiten acceder a la reconstrucción de bibliotecas, librerías y circuitos de lectura del siglo XIX (Zanetti; Parada, El orden y Cuando; Molina, "Lectoras").

Si la literatura del siglo XIX parecía cerrada y reducida a una decena de títulos, era simplemente porque no la veíamos o no la queríamos ver. Hay mucho más en el cielo y en la tierra decimonónica de lo que piensan, o pensaban, nuestras teorías (o, mejor dicho, nuestros prejuicios).

\section{Por qué volver al siglo XIX}

En realidad, nunca nos hemos ido del siglo XIX: en este se decidió el perfil de la llamada Argentina moderna y se cristalizaron también sus grandes paradojas. Cuando se clausuró la centuria, había un sistema republicano y un país constituido, pero la "sombra" de los caudillos (para usar una expresión sarmientina) y las redes de clan y de familia funcionaban de todas maneras como mecanismo constructor de poder. La Argentina era oficialmente un país blanco, o blanqueado por una inmigración europea que llegaba para colonizar el espacio vacío (sin eliminar por ello el latifundio terrateniente ni la concentración proletaria en las grandes ciudades). Sin embargo, el componente aborigen, formalmente borrado, siguió existiendo con la autonomía de lo inconsciente y oculto, emergiendo, por momentos, como el protagonista vergonzante, el "cabecita negra" o la "lengua del malón" (como apunta el expresivo título de Guillermo Saccomanno ${ }^{27}$ ) en la historia nacional.

Aunque la avanzada de las mujeres en nuestro siglo XIX fue notable en diversos frentes: literatura, cultura, política, el triunfo de la "sensibilidad victoriana" (Pedro Barrán) y el consiguiente relegamiento de las damas al gineceo, contribuyó, seguramente, a que la memoria de las antepasadas con voz propia y decidida iniciativa, que habían hecho política en las guerras civiles o se habían expuesto en la letra impresa, se diluyera en el discreto olvido. Que hubieran sido

26 La investigación de buena parte de este corpus novelesco por Eugenia Ortiz permite apreciar los debates y las fluctuaciones en torno a la creación de un proyecto de país y un imaginario nacional que se expresan en esa novelística variada y pujante, desdeñada luego por la selección canónica.

27 En la novela La lengua del malón (Buenos Aires: Planeta, 2003). 
pioneras y cofundadoras de la literatura nacional ${ }^{28}$ poco importaba, porque esa literatura misma no constituía la lectura más apreciada por las clases dirigentes cultas (así lo testimonian, en sus memorias, intelectuales como Victoria Ocampo y María Rosa Oliver) y porque, menos aún, podía interesar la mirada de las mujeres sobre una nación a la que siempre se llamaba "viril", cuando se deseaba elogiar sus glorias y laureles. Incluso hoy cuesta restablecerlas y establecernos como coprotagonistas de una sociedad que reconoce un padre de la patria (San Martín, el "gen" argentino ${ }^{29}$ ), pero no una madre donante de ese precioso ADN.

También la visión dicotómica que los dos Mansilla se empeñaron en trascender (Lojo, "Los hermanos"), la ferocidad de las oposiciones, la dificultad para establecer consensos razonados que no exigieran el mero aplastamiento del "otro" considerado el "enemigo", continuó y continúa marcando la vida política nacional.

Frente a ese panorama monocorde, Lucio y Eduarda Mansilla me sorprendieron como el jardín secreto de los caballeros de Malta, entrevisto a través del ojo de una cerradura; sorprende al viajero que pasa por Roma.

Sus libros son la punta del iceberg que alude a las complejidades tanto de una sociedad como de una literatura que aún desconocemos y que deberíamos conocer más profunda y extensamente, para comprender mejor el mundo en el que ahora vivimos y los recortes y mutilaciones de la memoria sobre los cuales nuestra autoimagen actual se construyó.

Como objeto de estudio y motor de la imaginación, reaparecen en mis textos de ensayo, y sobre todo en dos de mis novelas: La pasión de los nómades y Una mujer de fin de siglo. Este mes, en que se cumplen cien años de la muerte de Lucio, fuera de un país que en ese entonces no lo consideraba un gran escritor, sino un curioso personaje del pasado, ${ }^{30}$ creo que ambos, aún, tienen mucho para decirnos.

28 A pesar de las resistencias iniciales, su propio tiempo fue más generoso para reconocer su importancia. Cabe señalar que la entrada sobre Eduarda Mansilla de García figura bajo las correspondientes a su padre Lucio Norberto y su hermano Lucio Victorio, y precede a la de Juana Manso de Noronha en el Diccionario biográfico americano, de José Domingo Cortés, publicado en Madrid.

29 El gen argentino: buscando al argentino más grande se llamó un programa de televisión de 2007 conducido por Mario Pergolini y emitido por el canal Telefé, que buscaba al argentino/a dador de la identidad nacional, a través de las votaciones de los televidentes. El ganador fue José de San Martín, y los otros cuatro finalistas, en orden de votos, fueron: René Favaloro,Juan Manuel Fangio, Alberto Olmedo y Ernesto "Che" Guevara. Entre los diez finalistas hubo solo una mujer: Eva Perón.

30 "Mansilla fue un fracasado. [....] Diletante de todo, no logró especializarse; hombre de mundo en el sentido exclusivo de la palabra, no venció en política cuando el éxito ayudaba a todos, mediocres e inteligentes. En él, el conversador derrotó al literato, el dandy al hombre de acción. Poseedor de más talento que muchos de sus contemporáneos, ninguno lo consideró seriamen- 


\section{Obras citadas}

AA. VV. Historia de revistas argentinas (4 t.). Buenos Aires: Asociación Argentina de Editores de Revistas, 1997, 1999, 2001.

Alloatti, Norma Elena. "Memorias del viage a Francia: experiencias de una viajera argentina del siglo XIX". Decimonónica 8-1 (2011).

Alvarado-Larroucau, Carlos. "Les 'précieuses argentines': littérature francophone d'Argentine". Francofonía 18 (2009): 9-20.

Arambel-Guiñazú, María Cristina y Claire Emilie Martin. Las mujeres toman la palabra. Vol II.: Antología: escritura femenina del siglo XIX en Hispanoamérica. Madrid: Iberoamericana/Vervuert, 2001.

Area, Lelia. Una biblioteca para leer la nación: lecturas de la figura de Fuan Manuel de Rosas. Buenos Aires: Beatriz Viterbo, 2006.

Arfuch, Leonor. El espacio biográfico: dilemas de la subjetividad contemporánea. Buenos Aires: Fondo de Cultura Económica, 2002.

Auza, Néstor. Periodismo y feminismo en la Argentina: 1830-1930. Buenos Aires: Emecé, 1988.

Barrán, Pedro. Historia de la sensibilidad en el Uruguay. Montevideo: Facultad de Humanidades y Ciencias, 1991. Tomo I. La cultura 'bárbara' (1800-1860) y tomo II. El disciplinamiento (1860-1920).

Batticuore, Graciela. El taller de la escritora: veladas literarias de fuana Manuela Gorriti: Lima-Buenos Aires (1876/7-1892). Rosario: Beatriz Viterbo, 1999.

-. La mujer romántica: lectoras, autoras y escritores en la Argentina; 1830-1870. Buenos Aires: Edhasa, 2005.

Burke, Peter, ed. Formas de hacer historia. Madrid: Alianza, 1996.

Carrizo Rueda, Sofía. Poética del relato de viajes. Kassel: Edition Reichenberger, 1997.

-. ed. Escrituras del viaje: construcción y recepción de 'fragmentos del mundo'. Buenos Aires: Biblos, 2008.

Daireaux, Godofredo. "Ha sido indio". Tipos y paisajes criollos. Serie I. Buenos Aires: Prudent Hnos. \& Moerze, 1901. 95-100.

Cohen Imach, Victoria. Redes de papel: epistolas conventuales. Tucumán: Instituto Interdisciplinario de Estudios Latinoamericanos, Facultad de Filosofía y Letras, Universidad Nacional de Tucumán, 2004.

Duplancic de Elgueta, Elena. "La investigación argentina reciente sobre la literatura de viajes". Boletín de Literatura Comparada XXVI-XXVII (2001-2002): 97-105.

te, como tal vez lo mereciera en alguna ocasión. Y Mansilla, amargado, se fue al extranjero... Y a pesar de su talento y de su obra, será recordado sólo por su garbo y por sus aventuras" (así reza su necrológica en la revista $\mathcal{N}$ osotros, año 7 , tomo 12, 1913, 108). 
Even-Zohar, Itamar. "Polysistem theory (revised)". Papers in Culture Research. Tel Aviv: Porter Chair of Semiotics/Unit of Culture Research, Tel Aviv University, 2005. Figueiredo, Eurídice (org.) Conceitos de Literatura e Cultura. Niterói/Juiz de Fora: UFJF/EdUFF, 2010. ( $2^{\mathrm{a}}$. ed.).

Frederick, Bonnie (comp. y pról.) La pluma y la aguja: Las escritoras de la Generación del '80; Antología. Buenos Aires: Feminaria Editora, 1993.

-. Wily Modesty. Argentine Women Writers, 1860-1910. 1997. Tempe, AZ: Arizona State University/ Center for Latin American Studies Press, 1997.

Galán, Ana Silvia. La correspondencia epistolar entre familiares y amigos en la Argentina del siglo XIX. Las paradojas de la privacidad. Buenos Aires: Editorial Victoria Ocampo, 2004.

García Mansilla, Daniel. Visto, oído y recordado. Buenos Aires: Kraft, 1950. .

Gilbert, Sandra M., y Susan Gubar. The Madwoman In The Attic, The Woman Writer And The Nineteenth-Century Literary Imagination. 2 ed. New Haven: Yale University Press, 2000.

Goldchluck, Graciela y Pené, Mónica G. "Archivos de escritura, génesis literaria y teoría del archivo" [En línea]. I Jornada de Intercambio y Reflexión acerca de la investigación en Bibliotecología, 6 y 7 de diciembre de 2010. La Plata. Disponible en: http://www.fuentesmemoria.fahce.unlp.edu.ar/trab—eventos/ev.772/ev.772.pdf

-. (comp.). Palabras de archivo. Santa Fe: UNL y CRLA Archivos, 2013.

Gorriti, Juana Manuela. Obras Completas. Tomo I. Salta:

Fundación del Banco del Noroeste, 1995.

Hernández, Isabel. La identidad enmascarada. Los Mapuche de Los Toldos. Buenos Aires: Eudeba, 1993.

Iglesia, Cristina (comp.). El ajuar de la patria. Buenos Aires: Feminaria, 1993.

Kusch, Rodolfo G. La seducción de la barbarie. Buenos Aires: Raigal, 1953.

-.América profunda. Buenos Aires: Hachette, 1962.

Lewkowicz, Lidia. Fuana Manso (1819-1875): una mujer del siglo XXI. Buenos Aires: Corregidor, 2000.

Lojo, María Rosa. La 'barbarie' en la narrativa argentina (siglo XIX). Buenos Aires: Corregidor, 1994.

-. "El imaginario de las Pampas en francés: de Eduarda Mansilla a Guillemette Marrier". La función narrativa y sus nuevas dimensiones. Buenos Aires: Centro de Estudios de Narratología, 1999, 339-47.

-. Naturaleza y ciudad en la novelística de Eduarda Mansilla". De Arcadia a Babel: naturaleza y ciudad en la literatura hispanoamericana. Ed. Javier de Navascués. Madrid: Iberoamericana, 2002, 225-58. 
—. "El ramito de romero' de Eduarda Mansilla, o el conocimiento bajo especie femenina". Letterature d'America: Rivista Trimestrale Ispanoamericana XXII.90 (2002): 19-37.

—. "Por qué escribí La pasión de los nómades (1994): un libro y muchos viajes". Boletín de Literatura Comparada. XXVIII-XXX (2003-2005): 19-32.

—. "Los hermanos Mansilla: más allá del pensamiento dicotómico o cómo se escribe una Argentina completa". En tiempos de Eduarda y Lucio V. Mansilla. Córdoba: Junta Provincial de Historia de Córdoba, 2005. 15-41.

-. Una mujer de fin de siglo. Buenos Aires: DeBolsillo, Sudamericana, 2007.

-. La pasión de los nómades. Buenos Aires: DeBolsillo-Sudamericana, 2008.

—. "Las narrativas de la historia en el contexto de la globalización: el caso argentino". Alma América: in honorem Victorino Polo. Tomo I. Eds. Vicente Cervera Salinas y María Dolores Adsuar. Murcia: Universidad de Murcia, 2008. 371-385.

- . "Reescribir los orígenes en una huella secreta y alternativa". Rescrituras y transgenericidades. Dirs. Milagros Ezquerro y Eduardo Ramos Izquierdo. México: Rilma 2-ADEHL, 2010. 229-234.

-. "Sarmiento, crítico literario y promotor de mujeres escritoras: su lectura de Eduarda Mansilla". Visiones de Sarmiento. Eds. Miguel Ángel de Marco y Javier Roberto González. Buenos Aires: Facultad de Filosofía y Letras, Universidad Católica Argentina, 2010. 121-131.

- "Fronteiras, finisterras e corredores: do cliché ideológico a polisemia simbólica". Nas dobras do mundo a literatura acontece. Eds. Aroldo José Abreu Pinto, Madalena Machado y Walnice Vilalva. Sao Paulo: Arte e Ciência Editora, 2011, 287-313.

Mansilla de García, Eduarda. Pablo, ou la vie dans les Pampas. París: Lachaud, 1869.

-. Pablo, o la vida en las Pampas. Traducción de Alicia M.

Chiesa. Buenos Aires: Confluencia, 1999.

-. Pablo, o la vida en las Pampas. Estudio Preliminar de María Gabriela

Mizraje. Buenos Aires: Colección Los Raros, Biblioteca, 2007.

-. Creaciones. Buenos Aires: Imprenta Alsina, 1883. Edición crítica en prensa en la colección EALA, siglos XIX y XX, Corregidor, a cargo de Jimena Néspolo.

-. Mansilla, Eduarda. El médico de San Luis. Buenos Aires: Eudeba, 1962.

-. Recuerdos de viaje (tomo 1, ${ }^{a}$ ed. 1882). Pról. María Sáenz

Quesada. Buenos Aires: El Viso, 1996.

-. Recuerdos de viaje. Edición de Juan Pablo Spicer-Escalante. [s. l.]: Stockcero, 2006.

-. Lucía Miranda (1860). Edic., introd. y notas de María Rosa Lojo (dirección), con la colaboración de Marina Guidotti (asistente de dirección), Hebe Molina, Claudia Pelossi, Laura Pérez Gras y Silvia Vallejo. Madrid: Iberoamericana, 2007.

-. Cuentos (1880). Edición crítica de Hebe Molina. Buenos Aires: Ediciones Académicas de Literatura Argentina-Siglos XIX y XX-Corregidor, 2011. 
Mansilla, Lucio V. Retratos y recuerdos. Buenos Aires: Jackson, 1944.

-.Mis memorias: infancia y adolescencia. Buenos Aires: Hachette, 1954.

-.Entre-Nos: causeries de los jueves. Estudio Preliminar de Juan

Carlos Ghiano. Buenos Aires: Hachette, 1963.

-. Rozas. Buenos Aires: Malinca Pocket, 1964.

-. Una excursión a los indios ranqueles. Estudio preliminar y notas de Guillermo Ara. Buenos Aires: Kapelusz, 1966.

-. Diario de viaje a Oriente (1850-51) y otras crónicas del viaje oriental.

Edición crítica, introducción y notas de María Rosa Lojo (dirección) y equipo: Marina Guidotti (asistente de dirección), María Laura Pérez Gras y Victoria Cohen Imach. Buenos Aires: Corregidor, 2012.

Manso, Juana. Los misterios del Plata: episodios históricos de la época de Rosas escritos en 1846. Córdoba: Buena Vista, 2006.

Marco, Miguel Ángel de. Historia del periodismo argentino: desde los orígenes hasta el Centenario de Mayo. Buenos Aires: Educa, 2006.

Martínez, Julieta I. "Los misterios de París de Eugenio Sue: una ventana al siglo XIX". Históricas 89 (2010): 3-20.

Masiello, Francine. Between Civilization and Barbarism: Women, Nation and Literary Culture in Modern Argentina. Lincoln \& London: University of Nebraska Press, 1992.

-. La mujer y el espacio público: el periodismo femenino en la Argentina del siglo XIX. Buenos Aires: Feminaria, 1994.

Mayol Laferrère, Carlos. Tras las huellas de Mansilla: contexto histórico y aportes críticos a "Una excursión a los indios ranqueles". Córdoba: Ediciones del Copista, 2012.

Mizraje, María Gabriela. "Eduarda Mansilla o la familiaridad del triunfo". Argentinas de Rosas a Perón. Buenos Aires: Biblos, 1999. 129-51.

Molina, Hebe. La narrativa dialógica de fuana Manuela Gorriti. Mendoza: Editorial de la Facultad de Filosofía y Letras, Universidad Nacional de Cuyo, 1999.

-. Como crecen los hongos: la novela argentina entre 1838 y 1872. Buenos Aires: Teseo, 2011.

-. "Lectoras y escritoras en la Argentina de 1860: Margarita Rufina Ochagavía y M. Sasor". Anclajes XV.2 (2011): 31-47.

Navarro Floria, Pedro. "El salvaje y su tratamiento en el discurso político argentino sobre la frontera Sur, 1853-1879". Revista de Indias, LXI.222 (2001): 345-376.

—. "El desierto y la cuestión del territorio en el discurso político argentino sobre la frontera Sur". Revista Complutense de Historia de América 28 (2002): 139-168.

-. "La conquista de la memoria: la historiografía sobre la frontera sur argentina durante el siglo XIX". Revista Universum I.20 (2005): 89-111. 
Ortiz, Eugenia. Modelos de civilización en la novela de la Organización Nacional. Buenos Aires: Corregidor, 2012.

Parada, Alejandro. El orden y la memoria en la librería de Duportail Hermanos: un catálogo porteño de 1829. Buenos Aires: Facultad de Filosofía y Letras de la UBA, Instituto de Investigaciones Bibliotecológicas, 2005.

-. Cuando los lectores nos susurran: libros, lecturas, bibliotecas, sociedady prácticas editoriales en la Argentina. Buenos Aires: Facultad de Filosofía y Letras de la UBA, Instituto de Investigaciones Bibliotecológicas, 2007.

Quijada, Mónica. "La ciudadanización del 'indio bárbaro’. Políticas oficiales y oficiosas hacia la población indígena de la Pampa y la Patagonia, 1870-1920". Revista de Indias 59.217 (1999): 675-704.

Pérez Gras, María Laura. Relatos (de) cautivos: el legado literario de tres cautivos de los indios en la Argentina del siglo XIX. En prensa en el Portal Cervantes (Biblioteca Virtual Miguel de Cervantes de la Universidad de Alicante), 2013.

Prieto, Adolfo. El discurso criollista en la formación de la Argentina moderna. Buenos Aires: Sudamericana, 1988.

-. Los viajeros ingleses y la emergencia de la literatura argentina 1820-1850. Buenos Aires: Sudamericana, 1996.

Rivera, Jorge B. El folletín y la novela popular. Buenos Aires: Centro Editor de América Latina, 1968.

Rojas, Ricardo. Historia de la Literatura argentina: ensayo filosófico sobre la evolución de la cultura en el Plata. Los Coloniales I y II. Los Modernos II. Buenos Aires: Kraft, 1960.

Salomón Tarquini, Claudia. Largas noches en La Pampa: itinerarios y resistencias de la población indígena (1878-1976). Buenos Aires, 2010.

Sarmiento, Domingo Faustino. Facundo. Prólogo y notas de Alberto Palcos. Reedición ampliada de la edición crítica y documentada que publicó la Universidad Nacional de La Plata en Obras Completas (tomo I). Buenos Aires: Ediciones Culturales Argentinas, 1961.

-. Obras de Domingo Faustino Sarmiento. Tomo XLVI. A. Belin Sarmiento ed. Buenos Aires: Imprenta Mariano Moreno, 1900.

Sosa de Newton, Lily. Las argentinas de ayer a hoy. Buenos Aires: Zanetti, 1967.

-. Diccionario biográfico de mujeres argentinas: aumentado y actualizado. Buenos Aires: Plus Ultra, 1986.

—. ed. Narradoras argentinas: 1852-1932. Buenos Aires: Plus Ultra, 1995.

Szurmuk, Mónica. Miradas cruzadas: narrativas de viaje de mujeres en Argentina 1850-1930. México: Instituto Mora, 2007. 
Szurmuk, Mónica y Mckee Irwin, Robert, coord. Diccionario de estudios culturales latinoamericanos. México: Instituto Mora-Siglo XXI, 2009.

Tamagnini, Marcela. Cartas de frontera: los documentos del conflicto inter-étnico. Río Cuarto: Universidad Nacional de Río Cuarto, Facultad de Ciencias Humanas, 1995.

Toro, Alfonso y Fernando de, eds. El debate de la postcolonialidad en Latinoamérica: una postmodernidad periférica o cambio de paradigma en el pensamiento latinoamericano. Frankfurt/Madrid: TCCL-Iberoamericana/Vervuert, 1999.

Veniard, Juan. Los García, los Mansilla y la música. Buenos Aires: Instituto Nacional de Musicología, 1986.

Zanetti, Susana. La dorada garra de la lectura: lectoras y lectores de novela en América Latina. Rosario: Beatriz Viterbo, 2002. 